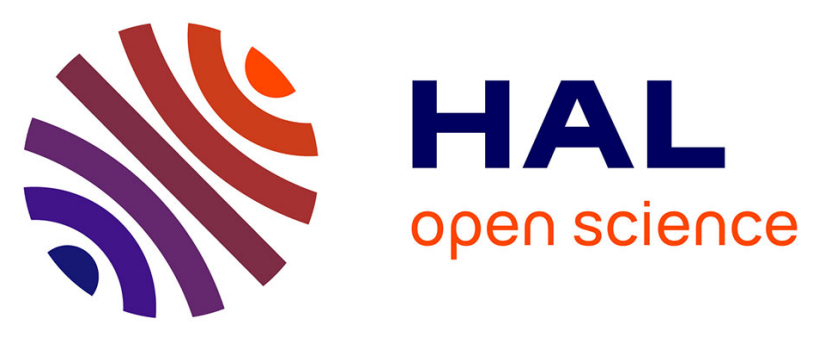

\title{
BISPHOSPHONATES ASSOCIATED OSTEONECROSIS OF THE JAW: A LONG TERM FOLLOW UP OF A SERIES OF 35 CASES OBSERVED BY GISL AND EVALUATION OF ITS FREQUENCY OVER TIME
}

Samantha Pozzi, Raffaella Marcheselli, Simona Falorio, Luciano Masini, Caterina Stelitano, Antonietta Falcone, Giovanni Quarta, Luisa Ponchio, Vincenzo V. Pitini, Stefano Luminari, et al.

\section{To cite this version:}

Samantha Pozzi, Raffaella Marcheselli, Simona Falorio, Luciano Masini, Caterina Stelitano, et al.. BISPHOSPHONATES ASSOCIATED OSTEONECROSIS OF THE JAW: A LONG TERM FOLLOW UP OF A SERIES OF 35 CASES OBSERVED BY GISL AND EVALUATION OF ITS FREQUENCY OVER TIME. American Journal of Hematology, 2009, 84 (12), pp.850. 10.1002/ajh.21553. hal-00521913

\section{HAL Id: hal-00521913 https://hal.science/hal-00521913}

Submitted on 29 Sep 2010

HAL is a multi-disciplinary open access archive for the deposit and dissemination of scientific research documents, whether they are published or not. The documents may come from teaching and research institutions in France or abroad, or from public or private research centers.
L'archive ouverte pluridisciplinaire HAL, est destinée au dépôt et à la diffusion de documents scientifiques de niveau recherche, publiés ou non, émanant des établissements d'enseignement et de recherche français ou étrangers, des laboratoires publics ou privés. 


\section{American Journal of Hematology}

WILEY

\section{BISPHOSPHONATES ASSOCIATED OSTEONECROSIS OF THE JAW: A LONG TERM FOLLOW UP OF A SERIES OF 35 CASES OBSERVED BY GISL AND EVALUATION OF ITS FREQUENCY OVER TIME}

\begin{tabular}{|r|l|}
\hline Journal: & American Journal of Hematology \\
\hline Manuscript ID: & AJH-09-0573.R1 \\
\hline Wutey - Manuscript type: & Letters \\
\hline Duthor: & 22-Sep-2009 \\
\hline Complete List of Authors: & $\begin{array}{l}\text { Pozzi, Samantha; Policlinico di Modena, Centro Oncologico } \\
\text { Modenese } \\
\text { Marcheselli, Raffaella; Policlinico di Modena, Centro Oncologico } \\
\text { Modenese } \\
\text { Falorio, Simona; USL di Pescara, Ospedale Santo Spirito, } \\
\text { Dipartimento di Ematologia } \\
\text { Masini, Luciano; Ospedale "Santa Maria Nuova" } \\
\text { Stelitano, Caterina; Pres. Osp. Riuniti "Bianchi, Melacrito, Morelli", } \\
\text { Divisione di Ematologia } \\
\text { Falcone, Antonietta; IRCCS "Casa Sollievo della Sofferenza", } \\
\text { Divisione di Ematologia } \\
\text { Quarta, Giovanni; Ospedale "A. Peerino", Divisione di Ematologia } \\
\text { Ponchio, Luisa; Istituto Scientifico Fondazione "S. Maugeri", Sezione } \\
\text { di Oncologia Medica I } \\
\text { Pitini, Vincenzo; Università di Messina, Dipartimento di Oncologia } \\
\text { Luminari, Stefano; Policlinico di Modena, Centro Oncologico } \\
\text { Modenese } \\
\text { Baldini, Luca; Ospedale Maggiore Policlinico MaRe, IRCCS, UO } \\
\text { Ematologia/CTMO }\end{array}$ \\
\hline Keywords: & $\begin{array}{l}\text { Support care, Quality of Life, Oncology, Neoplasia- } \\
\text { pharmacotherapeutics, Hematology/oncology- general }\end{array}$ \\
\hline
\end{tabular}

\section{S ScholaroNE" \\ Manuscript Central}




\title{
BISPHOSPHONATES ASSOCIATED OSTEONECROSIS OF THE JAW: A LONG TERM
}

FOLLOW UP OF A SERIES OF 35 CASES OBSERVED BY GISL AND EVALUATION OF ITS FREQUENCY OVER TIME

\author{
S. Pozzi (1), R. Marcheselli (1), S. Falorio (2), L. Masini (3), C. Stelitano (4), A. Falcone (5), G. \\ Quarta (6), L. Ponchio (7), V. Pitini (8), S. Luminari (1), L. Baldini (9) on behalf of Gruppo Italiano \\ Studio Linfomi (GISL)
}

(1) Centro Oncologico Modenese, Policlinico di Modena, Università di Modena e Reggio Emilia, (2) Dipartimento di Ematologia, USL di Pescara, Centro Diagnosi e Cura dei Linfomi, Ospedale Santo Spirito, Pescara, (3) Ospedale "Santa Maria Nuova", Reggio Emilia, (4) Divisione di Ematologia, Pres. Osp. Riuniti - "Bianchi, Melacrino, Morelli", Reggio Calabria, (5) IRCCS “Casa Sollievo della Sofferenza”, San Giovanni Rotondo, (6) Divisione di Ematologia, Osp. A. Perrino, Brindisi, (7) Sezione di Oncologia Medica I, Istituto Scientifico Fondazione S. Maugeri, Pavia, (8) Dipartimento di Oncologia, Università di Messina, Messina, (9) UO Ematologia 1/CTMO, Ospedale Maggiore Policlinico MaRe, IRCCS, Università degli Studi, Milan, Italy,

\footnotetext{
Running title: Follow-up of osteonecrosis of the jaw

Samantha Pozzi, MD

Department of Oncology and Hematology, University of Modena, Centro Oncologico Modenese, 41100 Modena, Italy.

Phone: +39.059 .422 .2175$

Fax number: +39.059 .422 .3707$

E-mail address: pozzi.samantha@unimore.it
} 


\begin{abstract}
:
Aims of the study were long term follow-up (FU) of bisphosphonates-associated osteonecrosis of the jaw (ONJ) in 35 cases observed by Gruppo Italiano Studio Linfomi (GISL) between 2002-2005 and the evaluation of its frequency in multiple myeloma patients over time. We asked the centres to up-date cases with $\mathrm{ONJ}$, and to report new cases of ONJ diagnosed between 2006 and 2008. After a median FU of 31 months, 19 patients are alive, 13 died, mainly from progression of the primary disease, and 3 patients are lost to follow-up. Treatment was mainly conservative, however 9 patients underwent surgery. Overall improvement was reported in 13 patients, 11 stabilized and 8 patients progressed. One patient relapsed after dental procedure. ONJ impacted quality of life, causing pain and interfering with the ability to eat. Although the frequency of $\mathrm{ONJ}$ in myeloma patients in the period 2006-2008 was slightly increased (3.6\% versus $1.9 \%$ in $2002-2005)$, we confirm the rarity of the complication.
\end{abstract}

Running title: Follow-up of osteonecrosis of the jaw 
(...) Bisphosphonates (BP) related osteonecrosis of the jaw (ONJ) is characterized by an avascular necrosis of the mandible or maxilla in patients receiving BP and not exposed to radiotherapy of head and neck. [1, 2]

In 2005 Gruppo Italiano Studio Linfomi (GISL) carried out a multicentric retrospective survey [3] reporting 35 cases of BP-related ONJ in cancer population, diagnosed between 2002 and 2005. In this new study, we report on long term follow up (FU) of the cases previously described, and the frequency of ONJ in multiple myeloma (MM) population over time in the same GISL centres.

For this purpose we asked the GISL centers to update the (...) evolution of ONJ and the quality of life of their patients after the diagnosis of ONJ. We also asked to report the number of MM patients receiving BP treatment in the period January 2006-June 2008, and the new cases of ONJ diagnosed at each center in the same period in the MM population, the prophylactic measures adopted, and any change in the schedule of administration of BP.

The diagnostic criteria utilized in this study were the same applied in our previous study [3] and included clinical and radiological findings of $\mathrm{ONJ}$, and the exclusion of cancer localization by biopsy, when performed. ONJ diagnosis was supported by typical radiological findings of osteonecrosis, sequestrum or lytic lesions with bone sclerosis and was confirmed by a dentist or maxillofacial surgeon.

The results showed that after a median FU of 31 months since the diagnosis of ONJ, 3 patients are lost to FU, 19 are alive while 13 patients died: 12 due to progression of the primary disease and 1 as a result of infection complicating ONJ. All the patients, except one, suspended BP administration at diagnosis of ONJ, but no one showed progression of skeletal related events by clinical evaluation. The treatment of the ONJ was mainly conservative, based on antibiotic and oral rinses. However 9 patients, with advanced stage, underwent surgery after conservative treatment. The surgery ranged from curettage (3 patients, all improved), to osteotomy ( 2 patients; 1 stable, 1 improved), ostheosynthesis (2 cases, both improved) and osteotomy with oromandibular reconstruction with fibula implant in one case. This patient died after surgery due to sepsis. Another patient received 
surgical treatment, the details of which were not further specified, and ONJ relapsed. The overall improvement of ONJ, after conservative and surgical treatment, was observed in 13 patients (12 patients improved and 1 resolved with healing of the lesion; 41\%), while 11 had stable disease (34\%) and 8 patients progressed (25\%). The progression of the ONJ was related to the development of fistula (4 cases), (...) or local infection (2 patients) and appearance or extension of exposed bone area. $(\ldots)$

ONJ reduced the quality of life of many patients, mainly due to pain, requiring pain relief treatment and interfering with the ability of eating in 15 out of 32 patients.

(...) The new estimated frequency in the MM population is slightly increased compared with the previous analysis. In the period 2006-2008, we observed 40 new cases of ONJ, over a population of $1108 \mathrm{MM}$ patients treated with BP reaching 3.6\%, compared with a frequency of $1.9 \%$ in 20022005, that corresponds to 28 cases over a population of 1402 MM patients

Discussion: BP-related ONJ is still not a fully understood condition, and pathogenesis and cofactors are still a matter of investigation. BP-associated ONJ has been recently defined by the American Society of Bone and Mineral Research [4] as a lesion in the maxillofacial area, characterized by exposed bone, not healing within 8 weeks, in patients treated with BP not receiving local irradiation. However in this definition the pathognomonic feature of the lesion is the bone exposure, that in our opinion is a late event, excluding from the diagnosis early stages of the disease. In 2005, at the time of our first study, there was no consensus definition of ONJ, and we defined BP-related ONJ based on clinical and radiological findings, exclusion of cancer localization when biopsy was performed, and confirmation by dentist or maxillofacial surgeon [3]. Exposed bone was considered a late manifestation of the phenomenon.

Currently, very few data about long term FU of ONJ are reported in literature $[2,5,6]$ and are summarized in Table 1.

Badros et al. [5] reported data of FU of 97 patients with ONJ from a Greek and US study, relating the evolution of ONJ with the evolution of MM. ONJ resolved in $62 \%$ of the cases, and no healing 
was observed over 9 months in 26\% (Table1). Surgery was performed in 36 patients, but no data about the outcome of ONJ after surgery are reported. With respect to evolution of MM, more frequent relapse of MM was observed in patients with recurrent or non-healing ONJ.

In another longitudinal FU from a single centre, Mehrotra et al. [6] analyzed the evolution of ONJ by stage, showing a better outcome for early stage compared with advanced stages, suggesting that early diagnosis and conservative treatment after suspension of BP may improve the evolution of the disease (Table1).

In consideration of the diagnostic criteria applied in our study, the staging system currently used cannot be applied. However, after a median FU of 31 months, we observed resolution in just 1 patient out of $32(3 \%)$, but stabilization or improvement in the majority of the cases (75\%). One patient out of $32(3 \%)$ relapsed after a dental procedure. The percentage of relapse is very low compared with the $12 \%$ reported by Badros et al. and it may be related to the fact that all but one of our patients suspended BP treatment.

Surgery, that seems to be a very controversial treatment for ONJ, in our study showed an improvement or stabilization of the lesion in 8 out of 9 patients, and we think that it may be considered in very advanced stages as already suggested by other authors [2]. In our case series, ONJ did not reduce the life expectancy of cancer patients, and death was mainly due to progression of the primary disease, although ONJ is not completely without risk, given that 1 death resulted from infection associated with surgical intervention of ONJ. We were however not able to make any correlation between evolution of $\mathrm{ONJ}$ and evolution of the primary disease.

The real frequency of BP-associated ONJ is not known but has been confirmed to be lower than $10 \%$ in many publications $[2,7,8]$. After the identification of ONJ, the majority of physicians in this study decided to discontinue BP administration regardless of bone disease, without reporting any progression of skeletal related events, which were clinically evaluated. Almost all the centres introduced a dental screening before the start of BP, and the administration of BP has been reduced to 2 years of treatment. However the introduction of prophylaxis in our study failed to 
reduce the risk of ONJ, as already described in literature [9] and benefits of the prophylaxis might be evaluated after a longer FU. In this sequential analysis, the frequency of ONJ was slightly increased in the period 2006-2008 compared with the period 2002-2005, but confirms data from literature $[7,8]$ that report the incidence of ONJ in MM population around $3 \%$.

In conclusion: even with the limits of a retrospective and observational study and a small number of patients, we can conclude that BP-related ONJ is a rare complication, that doesn't interfere with patients survival but reduces the quality of life due to pain and reduced ability of eating. It has a variable evolution, but can improve or stabilize in a high percentage of cases (75\%), with conservative and even surgical treatment in advanced stages, but rarely can heal. In our study, the incidence of ONJ is confirmed to be below 5\% in MM patients, and stable during this time period, despite the introduction of prophylactic measures.

Identification of the risk factors, better management and knowledge of ONJ evolution, will help clinicians to improve the outcome of $\mathrm{ONJ}$ and the quality of life of cancer patients. 


\section{FIGURES LEGEND}

Table 1: Evolution of BP-related ONJ in our case series compared with literature. ${ }^{*}$ The percentage refers to 32 patients (pts) over 35 (3 patients lost at follow-up). 


\section{REFERENCES}

1. Marx, RE. Pamidronate (Aredia) and zoledronate (Zometa) induced avascular necrosis of the jaws: a growing epidemic. J Oral Maxillofac Surg, 2003;61:1115-7.

2. Ruggiero, SL, B Mehrotra, TJ Rosenberg, and SL Engroff. Osteonecrosis of the jaws associated with the use of bisphosphonates: a review of 63 cases. J Oral Maxillofac Surg, 2004;62:527-34.

3. Pozzi, S, R Marcheselli, S Sacchi, L Baldini, F Angrilli, E Pennese, et al. Bisphosphonateassociated osteonecrosis of the jaw: a review of 35 cases and an evaluation of its frequency in multiple myeloma patients. Leuk Lymphoma, 2007;48:56-64.

4. Khosla, S, D Burr, J Cauley, DW Dempster, PR Ebeling, D Felsenberg, et al. Bisphosphonate-associated osteonecrosis of the jaw: report of a task force of the American Society for Bone and Mineral Research. J Bone Miner Res, 2007;22:1479-91.

5. Badros, A, T Evangelos, O Goloubeva, T Meiller, E Kastritis, E Verrou, et al. Long-Term Follow-Up of Multiple Myeloma (MM) Patients (pts) with Osteonecrosis of the Jaw (ONJ). American Society of Hematology; 2007 Dec 8-11; Atlanta. Blood, 2007;110:3519.

6. Mehrotra, B, Fantasia, J, Ruggiero,S. Outcomes of bisphosphonate-related osteonecrosis of the jaw-importance of staging and management guidelines:a large single institution update. American Society of Clinical Oncology; 2008 May 30-Jun 3;Chicago. J Clin Oncol, 2008.20526.

7. Wang, EP, LB Kaban, GJ Strewler, N Raje, and MJ Troulis. Incidence of osteonecrosis of the jaw in patients with multiple myeloma and breast or prostate cancer on intravenous bisphosphonate therapy. J Oral Maxillofac Surg, 2007;65:1328-31.

8. Hoff, AO, BB Toth, K Altundag, MM Johnson, CL Warneke, M Hu, et al. The Frequency and Risk Factors Associated with Osteonecrosis of the Jaw in Cancer Patients Treated with Intravenous Bisphosphonates. J Bone Miner Res, 2008.

9. Dimopoulos, MA, E Kastritis, C Bamia, I Melakopoulos, D Gika, M Roussou, et al. Reduction of osteonecrosis of the jaw (ONJ) after implementation of preventive measures in patients with multiple myeloma treated with zoledronic acid. Ann Oncol, 2009;20:117-20. 
1

2

3

4

5

6

7

8

9

10

11

12

13

14

15

16

17

18

19

20

21

22

23

24

25

26

27

28

29

30

31

32

33

34

35

36

37

38

39

40

41

42

43

44

45

46

47

48

49

50

51

52

53

54

55

56

57

58

59

60

\begin{tabular}{|c|c|c|c|c|c|c|}
\hline \multicolumn{2}{|c|}{$\begin{array}{l}\text { Badros et al. }{ }^{17} \\
\text { (97 patients) }\end{array}$} & \multicolumn{4}{|c|}{$\begin{array}{l}\text { Mehrotra et al. } 18 \\
\text { (94 patients) }\end{array}$} & \multirow{2}{*}{$\begin{array}{c}\text { Pozzi et al. } \\
\text { (32 patients)* } \\
\\
\%\end{array}$} \\
\hline & $\%$ & & $\begin{array}{c}\text { Stage I } \\
\text { (26 pts) } \\
\%\end{array}$ & $\begin{array}{c}\text { Stage II } \\
\text { (45 pts) } \\
\%\end{array}$ & $\begin{array}{c}\text { Stage III } \\
\text { (23 pts) } \\
\%\end{array}$ & \\
\hline not-healed & 26 & stable & 73 & 47 & 52 & 34 \\
\hline \multirow[t]{2}{*}{ resolved } & 62 & improved & 19 & 31 & 22 & 41 \\
\hline & & worsened & 8 & 22 & 26 & 25 \\
\hline recurred & 12 & relapsed & & & & 3 \\
\hline
\end{tabular}

Table 1: Evolution of BP-related ONJ in our case series compared with literature. *The percentage refers to 32 patients (pts) over 35 ( 3 patients lost at follow-up). 246x107mm (96 x 96 DPI) 